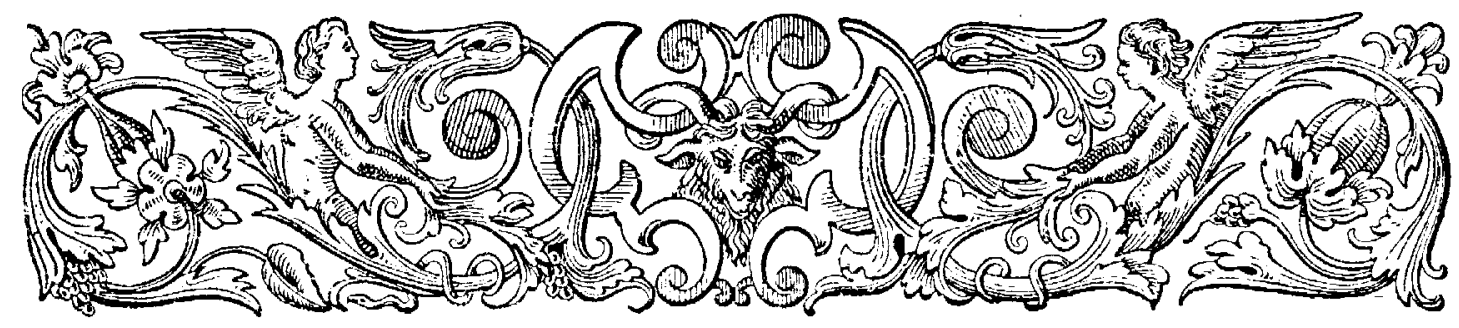

\title{
Nadere Mededeelingen over Kunstenaars en hun werk in betrekking tot Alkmaar
}

DOOR

C. W. BRUINVIS.

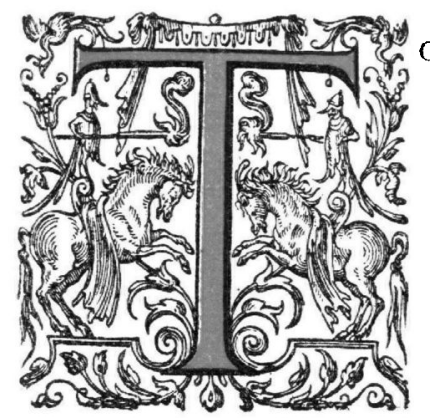

OEN ons in 1905 het verzoek der heeren drs. THIEME en BECKER bereikte om medewerking voor een "KünstlerLexikon", waren wij aanstonds genegen die te verleenen; maar overwegende, dat de uitgaaf veel meer jaren zou vorderen dan onze levenskans beloofde, meenden wij goed te doen om het door ons aangeteekende niet stuksgewijze maar in eens aan den dag te brengen, door het doen drukken en verspreiden van Levens schetsen van en Mededeelingen over Beeldende Kunstenaars, die te Alkmaar ge. boren zijn, aldaar gewoond of voor die stad gewerkt hebben. Wat wij sedert nog aangeteekend hebben is vervat in het hier volgende.

AELBERT JANSZ., in I63 I een der mede-oprichters van het schildersgild, ontving in $16_{54} f 6_{4}$ voor het beschilderen van eenige schuttervendels en overleed in September 1673 . In 1640,41 en 43 zijn kinderen van hem begraven 20 November 1647 werd er een met name LowiJs gedoopt; de moeder heette, Anna Lowijs. Den 27 December 1654 is hij hertrouwd met Burgert PIETERsD. 
$\mathrm{Zij}$ is in September 1656 begraven als BARbara PietersD. Een zoon uit het eerste huwelijk zal geweest zijn JAN AELbertsz., schilder, die den 9 September 1643 in het gild trad en den 5 Mei 1652 huwde met RoELofJe Voolmeyer.

ANSLIJN NiCOlaAszoon, NiColaAs, verkreeg den I4 Juni 1819 van den minister den eersten rang als onderwijzer honoris causa.

BARNEVELT, JACOB, beeldhouwer, in het gild gekomen 1728 , gehuwd 1729 met Gesina AsschenberG en begraven 3 Juni 1749. In 1743 werd hem voor het vervaardigen van een nieuw houten trompetter-beeld voor den Waagtoren betaald $f 5 \mathrm{I}$, waarvan $f \mathbf{I} \mathbf{I}$ voor het schilderen en vergulden. Het vorige beeld was in 1682 geleverd door MARIA GREFET, vour $f 34$.

BerG, Matthijs vaN DEN. Hij schilderde het portret van den alkmaarschen rector ReINERUs Neuhusius, waarnaar Suyderhoef en Holsteyn prenten sneden.

Blom, Hark Harksz, werd den 30 Juli i 728 lid van het S. Lucasgild.

BIJSTER, JAN. Ook in 1647 is hem voor glasschrijven $f 72$ door de stad betaald. Volgens EIKELENBERG was hij geen alkmaarder.

ClaAs Jaspersz. is begraven den 2 Juli I669. Aan hem is door de stad ook betaald in $1658 f 105$ voor een glas in de kerk te Krommenie, in $f$ 197: $16:-$ voor eenige gemaakte en herstelde glazen, en in 1659 $f$ 68:15:- voor het maken en instellen van een door SPARREBOOM geschilderd en gebakken glas in de kerk te Hensbroek.

Cluyt, Adriakn Pietersz, werd poorter van Alkmaar den I October I 594 .

Cluvt, Pieter Adriaensz., ontving in 1573 acht stuivers voor het maken van een kaart van het oosteinde der stad voor den prins de la Garde. In 1580 schilderde hij voor de doelens 2 groote tafereelen van het beleg der stad in I573, het eene uit het noorden, het andere uit het zuiden gezien. Beide stukken van historisch belang bevinden zich in het Stedelijk Museum; het eerste toont een samengesteld monogram, het tweede den vollen naam, Pieter Adriaensz. Cluyten.

Crescent, Jacobus Mattheus. De hem in $178 \mathrm{I}$ en 82 betaalde sommen voor herstelling van het groote kerkorgel betroffen voor $f 265$,het fatsoeneeren 
van de onderste beelden" (op het rugpositief) en voor $f$ 293: 10: - het vernieuwen van slingers, looden, bladeren, kransen, groote booglijsten, ornementen en 2 tropee's met muziek-instrumenten.

Croos, Anthonie. Eikelenberg merkte in een door hem geschreven uittreksel van het „Memoriaal gehouden bij Deeken en Raads van 't Schildersgilde" de namen van ANTONIE 1649 en van JACOBUS 1664 met een V, d. i. vreemde, daarmede te kennen gevende, dat zij geen geboren alkmaarders waren. Daarentegen laat hij de $\mathrm{V}$ weg bij PIETER CROOS, die in I65 I gildebroeder werd. Dat er 3 schilders dezer familie te Alkmaar gewoond hebben pleit wel voor hare betrekking op deze stad. Op I9 November I640 vonden wij de begrafenis geboekt van een kind van JuRIAEn Croos. KRAMm vermeldt eenige goede landschappen van een J. VAN CROos, waarvan een gejaarmerkt I66r, vermoedelijk van genoemden JACOBUS. Het Stedelijk Museum bezit twee schilderijen, de abdij en het slot van Egmond voorstellende, gemerkt I. V. Croos I68I.

Domer, Lambert. Het op gezag van V. D. Willigen en Kramm, ook in het Biogr. Woordenboek van V. D. AA, medegedeelde zal vermoedelijk geen JAQUES maar LAMBERT betreffen. De laatste portretteerde in $168 \mathrm{I}$ zeer verdienstelijk de drie regentessen van het mannengasthuis (het stuk hangt nu in het burgerweeshuis). Hij huwde, weduwnaar zijnde en in het proveniershuis wonende, den 7 Mei 1679 met Gees!e Esdra'sDr., weduwe van Gerrit Cornelisz. In I682 betaalde hij aan de stad $f$ 49:7:- voor een langs zijn huis gemaakte plating (walbeschoeiïn). In het bovengenoemde uittreksel van EIKELENberG lezen wij: "I684. nota ter dier tijt, verschil tegen DOMMER". LAMberTs vader, HERMAN geheeten, was een vergulder.

ELBERT OXkEnsz, glasschrijuer te Amsterdam, ontving van de stad Alkmaar in $1652 f 60$, in $1653 f 60$ en $f$ I20, respectievelijk voor glazen in de kerken te Graftdijk, Zijdewind en Nieuwe Niedorp.

Elten, Hendrik Dirk Kruseman van, oefende zich, na zijn leertijd te Haarlem, te Wolfheze en, na een reis door Duitschland, Zwitserland en Tyrol te Brussel, zich vervolgens tot 1863 te Amsterdam vestigende. Een in Maart I 868 ter tentoonstelling te Utica ingezonden groot schilderstuk, voorstellende een gezicht in het Shawanguk-gebergte op een najaarsdag, werd verkocht voor 3000 dollars. In 1870-73 bereisde hij Nederland, België, Duitschland, Frankrijk en Engeland en ontving hij te Amsterdam en Rotterdam veel eerbewijs. In $187 \mathrm{I}$ werd hij lid der Nationale Academic te New-York. Hij is den 2 I Juli I904 te Alkmaar begraven. 
Engelsman, Jan Maertensz. Hij schilderde in 1636 het glas, 't welk Hoorn aan de kerk te Schermerhorn schonk. In 1640 betaalde Alkmaar hem $f$ 246:10:- voor glazen in de kerken te de Rijp, Wormerveer en Krommenie, en $f$ 229: Io:- voor glazen in de kerken te Broek in Waterland en Etershem.

Essing, Jan. Een Jan Essex - vermoedelijk Essing - is den 30 Mei I645 begraven. De weduwe van den schilder, CATHARINA MiaERIË, kwam in I653 met attestatie uit 's Gravenhage bij de gereformeerde gemeente te Alkmaar.

Everdingen, Cesar Bovetus van. Een zijner zeven stukken in het Stedelijk Museum toont niet zijn bekende monogram, de aaneenverbonden letters $C, V$ en $E$, maar de vrijstaande letters $\mathrm{C} \mathrm{B} \mathrm{V} \mathrm{E,} \mathrm{alzoo} \mathrm{den} \mathrm{vollen} \mathrm{naam} \mathrm{aanduidende.} \mathrm{De}$ rechtsgeleerde Cesar Bovetus (zwager van BeAtrix Splinter) was geboren te 's Gravenhage, deed den 23 December I607 te Alkmaar den poorterseed, ondertrouwde aldaar den 27 Januari 1608 met Josina Lokvendr, werd den 24 Februari d. a. v. lid der gereformeerde gemeente en reeds begraven den I I Januari I610; kinderen van hem werden begraven den 25 Februari en den 12 Juni van hetzelfde jaar. De grootmoeder van CESAR v. E., die den 9 Februari I603 met attestatie van Haarlem bij de alkmaarsche gemeente $\mathrm{kwam}$, was een Griete Cesarsdr. Zijn vader Pieter v. E. trad den I3 Mei i6o i toe tot de gemeente, waartoe zijne moeder GRIETjE BuEkentop reeds sedert den 23 April van het vorige jaar behoorde.

Het stuk: Lycurgus toont de gevolgen der opvoeding, voormalig schoorsteenstuk der in 1656 verbouwde Prinsekamer van het stadshuis, is aan V. EverDINGEN in 1662 met $f 300$, het afbeeldsel van Wollebrandt Geleynsz. $\mathrm{DE}$ JONG ten voeten uit den 26 Juli $\mathrm{I} 674$ met $f 200$ betaald.

GerRit JANSz,, glasschrijver, en zijne vrouw Geertruyt Heynricksd. verkregen den 29 Juni 1654 van de gereformeerde gemeente attestatie naar die van Frankendaal.

Goltzius JANSz, JaCOB, plaatsnijder, werd den I 5 Mei I 599 poorter van Alkmaar, en JACOB GoltziUs van Haarlem den I December 1604. Een JACOB GoltziUs is begraven 14 October 1609 , een tweede $27 \mathrm{Juli} 163 \mathrm{I}$, de vrouw van een van beiden 9 April I620, eene dochter van Goltzius I4 Juni I6Io. In de

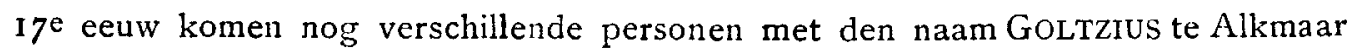
voor. Hun voorganger zal geweest zijn JoHAN, poorter geworden 13 December I 59I, den 2I April bevorens als weduwnaar ondertrouwd met MAGDALEENTJE VAN VARRISEEL, weduwe. 
HADSFELDT, WILLEM, als vreemdeling in $\mathbf{I 6 8} \mathbf{I}$ in het gilde gekomen, schilderde in het volgende jaar voor $f 75$ een nieuw stuk in den waaggevel.

Havenbergh, Willem. Hij werd gedoopt I3 Mei I685 als zoon van JAN H. en LIJSBETH JACOBS. In Januari 1750 vonden wij hem als stads-collecteur op turf en brandhout. Zijne vrouw werd begraven 3 September 1747. Een zoontje werd geboren in 1718 en overleed in Januari I719. In November van laatstgenoemd jaar werd eene dochter, NEELTJE, gedoopt.

HECK, ClaAs DirCKsz. vaN DER. Hij is niet overleden in het begin maar in het laatst van Januari $\mathrm{I} 649$.

Heck, Claes Jacobsz. van der. Zijne weduwe, Celitje van Wede, werd den 30 Maart I654 begraven.

Aan een der beide v. D. HECKEN is in $1636 f 48$ betaald voor een nieuw wit vaandel der schutterij.

Hoeve, Guillaume VAN DER, beeldsnijder, ontving in $1657 \mathrm{f} 80$ voor het snijden en vergulden van de lijst voor v. EVERDINGEN's groote schilderij van den adel der jonge schutterij (de witte en groene vendels). De beide zijkanten daarvan zijn in het Stedelijk Museum bewaard en pleiten voor de groote bekwaamheid van den vervaardiger. Voor het doek en het maken en vergulden van de lijst der andere schilderij, den adel der oude scbutterij (de roode en blauwe vendels), is in hetzelfde jaar $f$ I 29 betaald, maar het blijkt niet aan wien.

Holsteyn, Pieter. Aan hem is in 1650 door de stad $f$ I07:15:betaald voor "glasschrijven."

HoOghe, Romein DE. Bl. 21 , reg. I I v. o. staat I695, lees: 1694.

HOORNE, JORIS VAN, ontving in $166 \mathrm{I} f 75$ voor het snijden vall de roos in den zolder van de groote zaal van het stadshuis. Den 4 December $165 \mathrm{I}$ was een JORIS JACOBSZ., ongetwijfeld dezelfde, als beeldsnijder lid van het gilde geworden. Volgens EIKELENBERG was deze niet te Alkmaar geboren.

Horstok, Johannes Petrus van. Hij heeft in 1783 voor een nieuw schilderstuk in den voorgevel van het waaggebouw $f 2$ I 8 genoten. Zijne verhuizing naar Haarlem had plaats in 1801 .

Jongh, Gerrit Pietersz. DE, behoorde tot hen die in I63 $\mathrm{I}$ het schildersgild oprichtten. Gedurende het jaar 1635 was hij daarvan deken. In I636 werd hem $f \mathrm{I} 6$ betaald voor het schilderen met goud en zilver van acht koperen schilden, ten verzoeke van de kapiteins der jonge schutterij. In het Bisschop- 
pelijk Museum te Haarlem berust een door hem in 1630 vervaardigd, gansch niet onverdienstelijk, schilderij, voorstellende eene familie, waarachter de bouwval der kapel van O. L. V. ter Nood te Heiloo, met verschillende pelgrims in devotie. DE JONGH is begraven den 17 Mei 1642.

Kinnema, Johannes. Zijne eerste vrouw heette Clafsje Claesd., de tweede, die na zijn dood nog beviel van een zoon JoHANNES, gedoopt 7 Januari 1674, Wellemoet Jansdr. Tralijs.

Mathijs Jansz, beeldsnijder, ontving den 22 Februari i631 $f$ 26: 10:voor zeker snijwerk in de schepenkamer.

MENTON, Frans, zoon van JAN, was herkomstig van Haarlem en werd in 1580 poorter van Alkmaar. Vermoedelijk is hij, na zijne vrouw in 1582 verloren te hebben, hertrouwd en $z \mathrm{ijn}$ tweede vrouw den 26 Mei ${ }_{16} 606$ begraven. In ons artikel over hem is verkeerdelijk KRAMM voor IMMERzEEL genoemd.

Metius, DiRk. Deze heeft ook te Amsterdam gewoond, waar hij den 15 Februari I64I het poortersrecht kocht. Zijne beide stukken van 1649 (niet 1640) en 1650 in het burgerweeshuis te Alkmaar stellen de regenten van het mannengasthuis en het huisarmenhuis voor. In September 1653 dienden hij en zijne vrouw NiCOLLA NAGODT hunne attestatiën van de fransche kerk te Amsterdam bij de gereformeerde gemeente te Alkmaar in.

Meulen, Klaas Pietersz. van Der, is begraven 3 December 1693 (niet 1694). Hij huwde den 2 October I66I met Trijntje Siewerts, Sieuwerts of Sijverts in de kunstwereld'als Ca Tharina OOSTFRIES bekend en overleden I 3 November 1708, bij wie hij eenige kinderen heeft gewonnen. In 1673 is hem $f$ I 20 betaald voor het schilderen van een raam in de kerk te Graft, ten koste van den extrabuidel aldaar. Zijn zoon PIETER werd den 18 October 1695 als glazenmaker in het gilde opgenomen en mag dus niet tot de kunstenaars gerekend worden; daarentegen wel

Meulen, Sieuwert van DER, dien wij voor den tweeden zoon van KlaAs houden, al zochten wij te vergeefs de aanteekening van zijn doop. IMMERzEEL en KRAMM weten niet anders over hem te zeggen dan dat hij een goed teekenaar, etser en graveur was. Daar kan bijgevoegd worden, dat hij in 1700 in het gilde kwam, en dat voor de door A. VAN DER LAAN fraai gegraveerdetitelprent der Pharmacopea Almeriana, editio secunda, 1723, de teekening door hem is geleverd. 
Momper, Pieter, is in I648 lid van het schildersgilde geworden.

NaGtglas, MatThijs, als beeldhouwer in 1686 gildebroeder geworden, ontving in het volgende jaar $f 4^{2}$ voor het maken van twee houten beeldjes, die geplaatst werden op de makelaars van de vlas- en garenmarkt.

OUTGER JANSz, niet van Alkmaar geboortig, kwam in 1694 in het gilde als steenhouwer en glasschrijver. Hem werd door de stad betaald in I66 I $f$ I ro voor een glas in de kerk te Ursem en $f$ 7o voor een in die te Groet; en in $1664 f 75$ voor glazen in de kerken te Schermer en Grosthuizen, welke beide door SPARREBOom geschilderd waren.

Plas, Pieter van Der, beeldhouwer te Amsterdam, leverde in 1696 de marmeren beelden van de waarheid en de gerechtigheid boven den ingang van het stadshuis voor $f 475$.

Portman, Christiani Julius Lodewijk. Hij was geen fortuinlijk kunstenaar. Wellicht waren zijne historiestukken te groot van omvang om gading voor de liefhebbers te zijn. Tijdens zijne inwoning te Alkmaar hield hij zich niet alleen met grootsche ondernemingen, zooals de indijking van Zuiderzeegronden, maar ook met kleiner zaken bezig; zoo verkreeg hij in het laatst van 1849 een octrooi voor 5 jaren op de uitvinding van een vloeibaar doorhaalblauw voor linnen en andere witte stoften; ook moet door hem "Portmans-poetspomade" in den handel zijn gebracht. Zijn den 20 December 1826 geboren zoon ANToN LodewiJk ChristiaAN is, terugkeerende uit Japan, waar het hem voordeelig was gegaan, met de Ville de Havre verongelukt.

Roeterink, Reinier Evert Johannes, woonde in het begin van 1867 te Harlingen.

Ruyt, Jacobus De, huwde den 20 Juli i794 MARIA Hakmeyer, weduwe, begraven 22 Februari I799, en den 8 December van dat jaar MARIJTJE VEeN, overleden 24 December I808. Den I0 Mei I802 werd hem eene acte verleend als verkooper van koffie, thee en chocolade, hetgeen doet denken dat de kunst hem karig brood verschafte.

Sparreboom, Cornelis Jansz. Voor geschilderde kerkglazen is hem mede betaald: Hensbroek I659 $f$ I00, Schermer en Grosthuizen I665 $f$ r 20 , Obdam I665 $f$ 70, Warder I67I $f$ 50. Hij huwde den 25 Augustus 1658 voor burgemeesteren met TRIJN CLAESD., die hun reeds in de vorige maand gedoopt kind op den arm droeg. $Z_{i j}$ schonk hem vervolgens nog vier kinderen en werd begraven 
Io Januari 1685. SparReboom hertrouwde den 24 April 1689 - in de publieke kerk - met ARIAENTJE JacobSD. HaERLAey en mocht zich nog tweemaal met een wiegekind verblijden.

Steen, Jan, was een zoon van Cornelis Jansz. Steen, stadsbode, en TRIJNTJE JANSD. en werd gedoopt den 2 I Januari 1685. In Augustus I7r I huwde hij te Amsterdam met Johanna Lanson; van hen werd den I9 Maart I7I9 een zoon gedoopt, begraven ro Juni d.a.v. Zij werd den I9 Maart van het volgende jaar begraven. Uit STEENS tweede huwelijk in I721 zijn niet minder dan tien kinderen geboren; dezer moeder EliSabeth SEullijN werd den I4 Januari I74I ter aarde besteld.

Steur, Gerrit van Der. Voor het vergulden van de lijst van het door hem in 1725 gemaakte schilderstuk in den voorgevel van het waaggebouw werd hem $f 22$ betaald.

Streek, HeNdrik vaN. Voor vier burgemeesterswapens aan de Hooge Steenenbrug werd hem in $1696 f 200$ voldaan; en voor het leveren en maken van een wapensteen in 1693 aan hem en JAN GIJSELINGH, mede te Amsterdam, samen $f$ 159: I6:-

Teerling, Arendt Samuelsz, had tot vrouw Marijtje Pietersd. Kinderen van hem zijn gedoopt in 1644,45 en 48 .

VISSER, ADRIANus DE, ondertrouwde den 18 Januari I80 I met AAFJE IVANGH, van Bergen. Uit hun huwelijk zijn tot in 1806 zes dochters geboren. Zijne benoeming tot stads-teekenmeester, voor bouwkundig en handteekenen (onder het laatste verstond men het teekenen van koppen en andere lichaamsdeelen) geschiedde in Juli I 825 .

VREE, NiCOLAAS DE. Hij was vermoedelijk doopsgezind, zijne vrouw Catharina DE Blom roomsch, want den i 8 Mei 1696 werd zijne 22jarige dochter CATHARINA, ,bekeerd uit het mennonisme”, in de r. k. St. Laurenskerk gedoopt, waarbij getuigen waren CATHARINA DE BLOM en BAEFJE JANS. Deze dochter is den 5 Mei 1739 begraven.

Washuizen, Abraham, kwam in het gilde den 12 December 1769 en verliet het en de stad r782. Hij was gehuwd met CecILIA KuIPER; kinderen werden gedoopt in 1754,56 en 63 . 


\section{AANVULLING VAN DE LIJST DER LEDEN VAN HET ST. LUCASGILDE TE ALKMAAR.}

Dr. A. VAN DER Willigen Pz. gaf in De Nederlandsche Spectator nr. 2 I van I867, bl. I6I, eene „naamlijst der gildebroeders van het St. Lukas Gild te Alkmaar", en nogmaals verscheen een dergelijke in het tweede deel van OBREEN's Archief voor Nederlandsche Kunstgeschiedenis, 1879/80, bl. 26. De redacteur was daartoe in staat gesteld door den gemeente-secretaris van Alkmaar, die hem het ledenboek verstrekt had. Dit boek was echter niet het oorspronkelijk memoriaal van deken en raden, maar een omstreeks 1730 daaruit opgemaakt register, waarin de vervolgens gekomen leden werden bijgeschreven. Het oude memoriaal is niet meer voorhanden, maar een uittreksel daarvan, door SrMoN EIKELENBERG vervaardigd, overtuigt ons, dat de schrijver van 1730 zich niet alleen wel eens in de data vergist, maar ook sommige namen overgeslagen heeft. Zoo ontbreken:

1636. AlLERT HARCXz. en Gillis SCHAGEN.

1638. SIMON DIRKSZ. ORSIN.

I646. SIMON KEISER.

I649. JAN VAN DEN BERGH.

I658. ISAäK UILENBURG.

i663. Harmen KluisenaAR en Barend le Petit. ${ }^{1}$ )

I664. JACOBUS KROOS.

En bepaaldelijk als beeldsnijders:

i63i. MatThijs Jansz.

I649. JAN DiRKsz. HuYG, van Medemblik.

EIKELENBERG, die trouwens niet meer dan een uittreksel gaf, en niet naar alphabetische maar na tijdsorde, vermeldt, evenmin als de naamlijșt, den schilder Ja N Schagen, die in 1636 een leerling had.

Van de glasschrijvers, die in het ledenboek onder de (in OBREEN's Archief onvermeld gebleven) glazenmakers zijn opgenomen, noemt hij; I644 JAN BIJSTER, 1650 Gerrit Jansz. Soltin, 1655 Cornelis Jansz. Sparreboom en i660 KlaAs Pietersz. van der Meulen, maar niet 1665 Claes Jaspersz.

1) Onze bron noernt den laatste wel niet, maar wij nemen hem hier mede op, omdat wij reeds vele jaren geleden reden vonden, om zijn naam op onze lijst der gildebroeders bij te schrijven. 
124 NADERE MEDEDEELINGEN OVER KUNSTENAARS EN HUN WERK, ENZ.

Bovengenoemde BAREND LE PETIT zal wel dezelfde geweest zijn als B. LE PETIT, die, volgens NAGLER, geboren hollander en omstreeks i650 te Rome werkzaam was, landschappen en bouwvallen schilderde, en als B. L. PETIT volgens eene aanteekening van GERARD HOET Jr. de leermeester van PAULUS POTTER; en van wien KRAMM een in I76o verkocht schilderij vermeldt, voorstellende het slot te Egmond aan den Hoef, dat zeer goed een vrucht kan zijn geweest van 's mans verblijf te Alkmaar.

EIKELENBERG teekent nog aan: „26 November $1649 \ldots$. de zoon van JACOB JANSZ. TURK. 3 gl.", maar voegt er niet bij als hoedanig deze lid werd; misschien was hij beeldsnijder, want zijn vader, Groote Turk genoemd, maakte in 1643 het houtwerk en de kas van het groote orgel in de S. Laurenskerk.

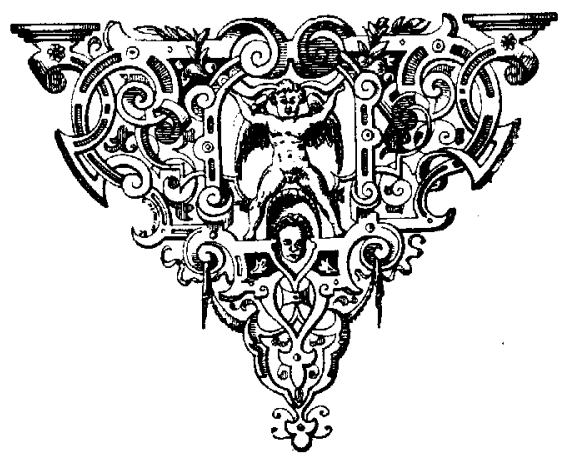




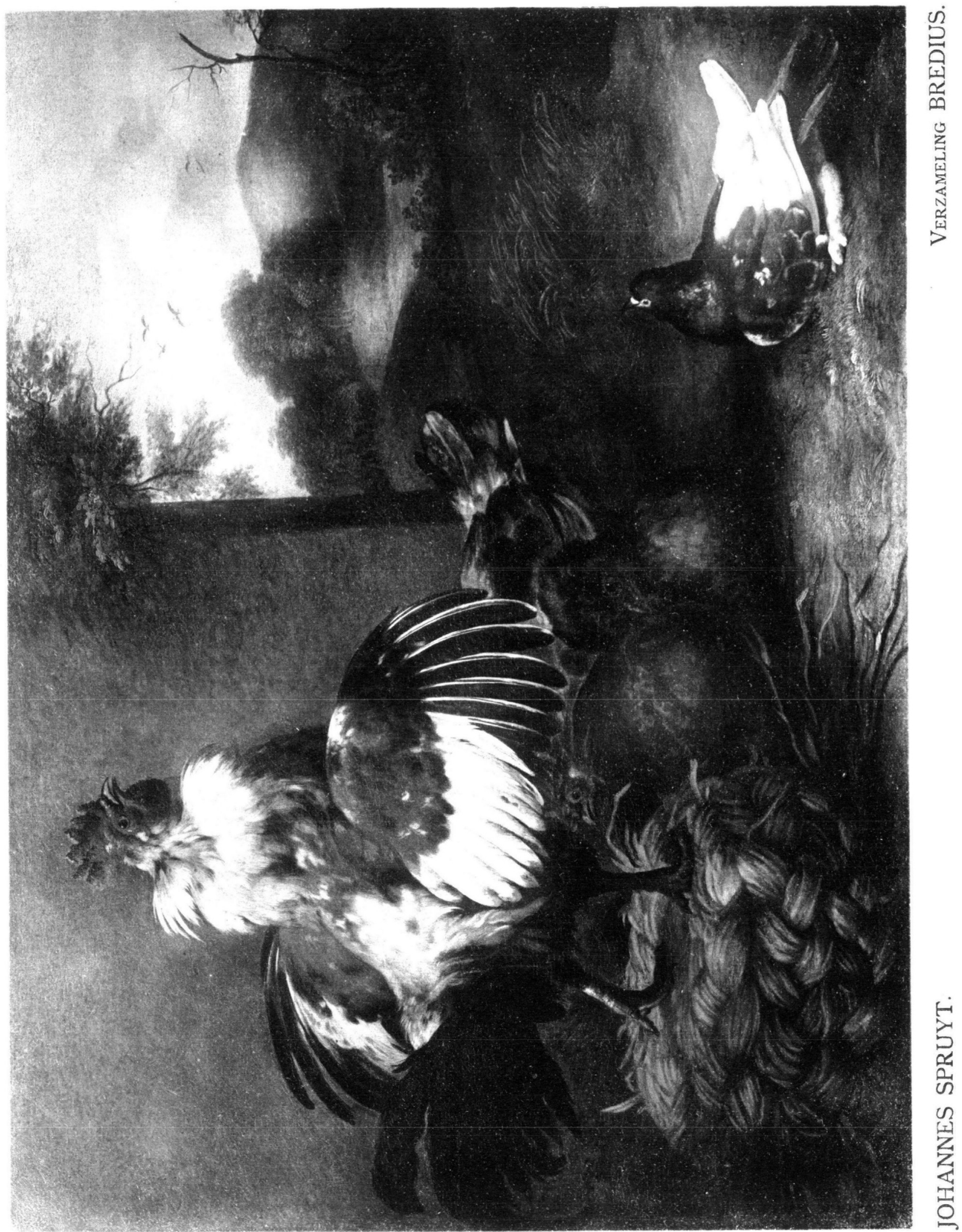

